\title{
IMPACT OF DEMOGRAPHIC FACTOR INCOME ON THE DECOY EFFECT FOR TWO EXAMINED PRODUCTS CATEGORIES
}

\author{
[Vliv prŕjimu jako demografického faktoru na efekt návnady u dvou typů \\ zkoumaných produktů] \\ Radka Kubalová ${ }^{1}$ \\ ${ }^{1}$ Silesian University, School of Business Administration, Univerzitní nám. 1934/3,733 40 Karviná \\ Email:kubalova@opf.slu.cz.
}

\begin{abstract}
According to the previous research about consumer behaviour, adding a decoy option (inferior option) to a set of original options often increases the individual's preference for one option over the other original option. In this paper, the possible impact of income as a traditional demographic factor on the phenomenon is explored and discussed in the case of two product categories: washing machines and gym season-tickets. The analysed data were obtained in an online experiment with 260 participants where the presence of the decoy effect has been confirmed for the two mentioned product categories. The effect sizes for consumer groups based on the income level are tested by Chi-squared test. It was found out that not all income categories display the decoy effect and the income categories which exhibited the decoy effect differed between the two examined product categories. The strength of the decoy effect was proved to be dependent on the income category.
\end{abstract}

Keywords: attraction effect, consumer decision making, context effects, effect of asymmetrically dominated alternatives, choice, season tickets, washing machines.

JEL classification: D91

Received: 1.10.2020; Reviewed: 28.10.2020; 9.12.2020; Accepted: 27.1.2021

\section{Introduction}

The market is consisting of billions of individuals each with their own set of needs, lifestyle and behaviours. While it is impossible to focus on every individual, the process of segmentation allows the company to divide the customers and consumers into several homogenous groups based on similar characteristics, described by similar behaviour patterns or needs which allows the companies to easily focus and target the whole group of customers who will most likely act and respond to marketing mix in a similar way. Although demographic and geographic segmentation is the oldest method and factors like personal believes, attitudes and motivations became more valuable, according to Bartoli and Varini (2011, pp. 3) the most common approaches to market segmentation still involve geodemographic and geographic variables, also due to the ease of data collection in the Internet era. Therefore, the collection of demographic data to characterize the consumers, including the income variable, became rather a basic necessity today.

This paper is focused on the phenomenon of decoy effect which illustrates the importance of consumer psychology, of understanding how consumer perceive the products and how consumers judge and compare the products' attributes before making a purchase. The goal of the paper is to explore the possibility of income as a demographic factor impacting the decoy effect and therefore, uses the traditional data about the consumer to increase the understanding of such market dynamics like the decoy effect.

The paper is structured in following way. In the first section, literature review about the decoy effect and its moderators with the focus on demographic factors is introduced. The next section is dedicated to the methods of the research and the process of data collection and 
analysis. Finally, the descriptive statistics and results of conducted Chi-squared tests are presented, just as well as the research limitations in the last chapter.

\section{Literature review}

Ever since the decoy effect has been introduced and described by Huber, Payne and Puto (1982), it became one of the most explored context effects, discussed in both laic and scientific public. By design, the decoy is such an alternative of the product in the choice set which is inferior in at least one dimension to another alternative in that choice set or in other words, the decoy is dominated by another alternative. Another important feature of the decoy is that the decoy is never designed to take the dominant's share for itself. When such decoy alternative exists in the choice set, the dominant alternative likelihood to be chosen raises in comparison to when the decoy is not present. Three meta-analyses suggest that decoys can increase the likelihood of choosing the dominating alternative by 12 to $18 \%$ (Heath and Chatterjee 1995; Milberg et al. 2014; Yang and Lynn 2014). Moreover, the empirical testing in the real market by $\mathrm{Wu}$ and Cosguner (2020) implies $14.3 \%$ raise in gross profits for the retailer due to the decoy effect which supports the possible practical implications for the managers.

Traditionally, the studies like those of Ariely and Wallsten (1995), Choplin and Hummel (2005), Pettibone and Wedell (2007) and more others are focusing on explaining the underlying mechanisms of the effect or examining the effect on different types of subjects, typically consumers but also children (Zhen and Yu 2016) or animal species subjects like hummingbirds (Bateson, Healy and Hurly 2003) or rhesus macaques (Parrish, Evans and Beran 2015).

Recently, attention is also paid to the factors which might moderate the effect. The moderators could be divided to the situational variables (or so called experiment design moderators) where belong the conditions under which the decision making is a taking a place. For example, the role of the presentation format of the alternatives and their attributes was described by Frederick, Lee and Baskin (2014), Ha, Park and Ahn (2009) or Yang and Lynn (2014) and it was found out using a pictorial or qualitative verbal description of the alternatives tend to attenuate the effect. Moreover, Chuang and Yen (2007) found out if the alternatives' description includes a negative products' country of origin then the decoy effect decreases. Other situational moderators could be choice or time constraints as explored by Dhar and Simonson (2003) or Lin et al. (2008).

Beside the situational variables, there were reported also person-based or individual specific variables connected to the characteristics of the consumers. Similarly as in purchase models and purchase motivation models based on theory of reasoned action and planned behaviour of Ajzen and Fishbein (2005, pp. 194), the consumer's traits also determine how external stimuli affect them even in case of decision making involving the decoy alternatives. Therefore, examining such moderators as motivational influences (Levav, Kivetz and Cho 2010) or thinking styles (Mao and Oppewall 2012) but also traditional socio-economic and demographic factors has its place in the research about the context effects, including the decoy effect.

In most of the studies like Rogers, Vargas and Voigt (2020) or Kaptein, Emden and Iannuzzi (2016) it can be observed the socio-demographic data about the participants are collected in the experiments without analysing them further. There can be traced few studies that did examine the effect in relation to some of the demographic factors, like gender and age. 
Duriník (2013) and Kubalová (2020) found out the success rate of decoy effect differs between males and females and that men exhibit stronger decoy effect while women are more likely to choose the target option with no decoy included in the choice set. Wu and $\mathrm{Yu}(2018)$ found mental fatigue increases the decoy effect in males but not in females. Meanwhile, according to Kim and Hasher (2005) who connected the aspect of age to the level of knowledge in different decision tasks involving the decoy effect older adults show more consistent decisions than younger adults, similar results of older age groups being less likely to show the irrational preferences is previously reported by Tentori et al. (2001). Inconsistent with their findings, Kubalová (2020) reports older adults tend to exhibit stronger decoy effect leading to changing their preferences more than younger adults. However, the different results between the studies could be possibly explained by the different nature of decision making tasks (routine vs. less frequent decision/purchase) and/or products' level of involvement (low involvement product vs. high involvement product) used across the studies. It is not known to the author there would be any focus paid to the other demographic factors besides these mentioned, including the income. The lack of previous focus on the income factor leaves space to explore how the introduction of asymmetrically dominated decoy is effective among different income segments for two different types of products.

\section{Research methods and data}

The aim of this study is to analyse the impact of a demographic factor income on the strength of the decoy effect. The research question was whether consumers of all income categories succumb to the decoy effect and whether there are any differences in the effect strength between the different income categories. To meet the aim of the research, the following work hypotheses were constructed:

H1: The decoy effect can be observed between all consumers, no matter of the income category.

$\mathrm{H} 2$ : The popularity of the target alternatives is not independent on the income category.

$\mathrm{H} 3$ : The growth of the target share is not independent on the income category.

By the first hypothesis, it is supposed that all income categories are prone to exhibit a positive decoy effect while the other two hypotheses assume when it comes to the strength of the decoy effect (for each examined product and between the products) there is a relationship between the effect and the income category.

The study uses the data from a previously conducted online experiment which was focusing on the decoy effects for four product categories and the data obtained were used to test the statistical significance. The author's choice of products involved was random with the aim to include both intangible and tangible products. The other criterion was to use products which were not previously nor frequently used in the previous research about decoy effects unlike products like microwaves or computers used in studies of Dhar and Simonson (2003), Ha, Park and Ahn (2009), Lin et al. (2008), Yang and Lynn (2014) and even many more. Out of the four examined product categories in total, the decoy effect was confirmed to be statistically significant only for two products: washing machines and gym season-tickets. The products lunch menu and vacations for which the decoy effect was not detected were excluded from the further analysis and only the washing machines and gym season-tickets were deemed suitable to be included in the analysis to determine impact of income on the decoy effect.

Each alternative in the choice set was described by two characteristics and the price. The alternatives of gym season ticket were characterized by number of gym entries, 
presence/absence of sauna entry and price. The washing machines were described by number of revolutions, the volume and price.

In order to detect the effect of decoy on the respondents' choices, there were two versions of surveys presented, one for control group with only a competitor item and a target item (Set A) and another one for an experimental group which included a competitor item, a target item and a decoy option (Set B). As a target item we label the dominant alternative or the one option which is dominating the decoy in at least one characteristic while competitor is the remaining alternative in the choice set.

In total, 570 potential participants from general public were addressed in total via Facebook in March 2018. 260 participants reacted positively and filled out the survey that was sent to them via a website link - 128 in the control group and 132 in the experimental group. The respondents were divided to the control/experimental group based on an alphabetical order of the first letter of their surname to avoid intentional and unintentional manipulation. Each subject participated voluntarily and no reward was promised or given for the participation.

The existence and the strength of the decoy effect were then measured as the difference between the assumed normative control condition and the decoyed condition choice shares for target (T) and competitor (C). The proportion of subjects choosing the target option $\mathrm{T}$ in the control condition (Set A) which consists of options $\mathrm{T}$ and $\mathrm{C}$ is therefore written as:

$$
p(T, A)=\frac{T_{A}}{T_{A}+C_{A}}
$$

Alternatively, the proportion of subjects choosing the competitor option (C) in the control condition (Set A) containing options $\mathrm{T}$ and $\mathrm{C}$ is therefore written as:

$$
p(C, A)=\frac{C_{A}}{T_{A}+C_{A}}
$$

In the experimental condition (Set B) which contains also the asymmetrically dominated alternative $\mathrm{D}$ beside the target $\mathrm{T}$ and the competitor $\mathrm{C}$. The author did not include in the target share also the share of the decoy itself which has been done also in the previous studies of Kim and Hasher (2005) or Duriník (2013) who in their analysis consider the decoy synonymous with the target alternative. The author of this study leans towards the opinion that combining the target and the decoy can be done in the cases when the decoy is the same version of the target with lower characteristics (e.g. higher margin option developed to an existing product line) and therefore in practice, it might not be important for the seller if the consumer chooses the target or the asymmetrically dominated version of the target which is the case of this study as well. However Yang (2013) criticizes this approach as it is possible it could lead to boosting the decoy effect and making it easier to prove it is statistically significant. To avoid this, we decided to measure only the shift of popularity of the competitor and the target itself without the share earned by the decoy. Consequently, the proportion of subjects choosing the target option (T) and the competitor (C) in the experimental condition are defined similarly as in the control group as:

$$
p(T, B)=\frac{T_{B}}{T_{R}+C_{R}}
$$




$$
p(C, B)=\frac{C_{B}}{T_{R}+C_{R}}
$$

Since the numbers of participants in experimental $(\mathrm{N}=132)$ and control groups $(\mathrm{N}=128)$ and even among the income categories were not equal the chi-squared test was conducted between the observed choices TB and CB in the experimental group and the expected choices based on the assumed normative control condition and the sample size $(\mathrm{TB}+\mathrm{CB})$. Using this approach, it allows taking into consideration what would be the distribution of choices in the normative control group if the group size equals the experimental group and therefore, it helps diminish the differences given by the uneven group sizes. Therefore, the expected choice shares of target $(\mathrm{T})$ and competitor $(\mathrm{C})$ were calculated using following formula:

$$
\begin{array}{cc}
\left(T_{B}\right)=p(T, A) *\left(T_{B}+C_{B}\right) ; & E\left(T_{B}\right)=\left(\frac{T_{A}}{T_{A}+C_{A}}\right) *\left(T_{B}+C_{B}\right) \\
E\left(C_{B}\right)=p(C, A) *\left(T_{B}+C_{B}\right) ; & E\left(C_{B}\right)=\left(\frac{C_{A}}{T_{A}+C_{A}}\right) *\left(T_{B}+C_{B}\right)
\end{array}
$$

\section{Empirical results and discussion}

In this chapter, the results of consumers' decision making when the decoy was excluded and included in the choice sets are presented with the focus on the different income categories. Firstly, a brief descriptive statistics is presented to introduce the characteristics of the control group and the experimental one. The main part of the chapter discusses the relationship between the income and decoy effect which is explored and tested using the Chi-squared tests. The end of the chapter is dedicated to the possible limitations of this research.

\subsection{Descriptive statistics}

The Table 1 shows the distribution of the participants in the control and the experimental group based on the sociodemographic factors such as gender, age and income.

Table 1: Characteristics of the sample

\begin{tabular}{|l|l|l|l|}
\hline $\begin{array}{l}\text { Characteristics of } \\
\text { respondents }\end{array}$ & Demographic groups & $\begin{array}{l}\text { Control group } \\
\mathrm{N}=128\end{array}$ & $\begin{array}{l}\text { Experimental group } \\
\mathrm{N}=132\end{array}$ \\
\hline Gender & Male & $46 \%$ & $54 \%$ \\
& Female & $54 \%$ & $46 \%$ \\
\hline Age & $18-27$ & $24 \%$ & $44 \%$ \\
& $28-37$ & $6 \%$ & $19 \%$ \\
& $38-47$ & $23 \%$ & $21 \%$ \\
& $48-57$ & $24 \%$ & $10 \%$ \\
& $58+$ & $23 \%$ & $6 \%$ \\
\cline { 2 - 4 } & Median & $38-47$ & $28-37$ \\
& Modus & $18-27 ; 48-58$ & $18-27$ \\
\hline Income & Up to 10 000 CZK & $28 \%$ & $25 \%$ \\
& $10001 \mathrm{CZK}-20000 \mathrm{CZK}$ & $35 \%$ & $26 \%$ \\
& $20001 \mathrm{CZK}-30000 \mathrm{CZK}$ & $21 \%$ & $14 \%$ \\
& Over 30 000 CZK & $16 \%$ & $10001 \mathrm{CZK}-20000 \mathrm{CZK}$ \\
\cline { 2 - 4 } & Median & $10001 \mathrm{CZK}-20000 \mathrm{CZK}$ & $10001 \mathrm{CZK}-20000 \mathrm{CZK}$ \\
\hline
\end{tabular}

Source: own data

In the control sample, $54 \%$ of respondents were female while in the experimental group $54 \%$ were male. The median age was 28-37 years in the experimental group and 38-47 years in the control group and it can be generally stated the both samples were made of rather younger age groups as modus age in both groups was between 18-27 years in both groups and in the control group, the modus age was also $48-57$ years. When it comes to the income categories, 
the category with the income between $10001 \mathrm{CZK}$ to $20000 \mathrm{CZK}$ was the most frequent and median category in both examined groups. This category is clearly below the current Czech wage median which is $29123 \mathrm{CZK}$ according to the Czech Statistical Office (2020). For the purpose of research focusing on the income as demographic factor, it was found positive that the differences in income categories between the experimental and the control group were low, if not minimal. The high proportion of younger generations with lower income might be the result of using social media platform as a mean to address potential participants as of July 2020, it was reported by website Statista.com (2020) that the largest age group of Facebook users were men and women between the ages of 25 and 35 years, and men and women between the ages of 18 and 24 years constituted as the second largest demographic group of Facebook users.

\subsection{Impact of income on the decoy effect}

Using the formulas introduced in the previous chapter, the proportions of subjects who choose either competitor, target or the decoy were calculated and the results are presented for each income category in the following Table 3. The table presents also the results of the Chisquared test of independence (conducted with conditions of $\alpha=0.05$ and $\mathrm{df}=1$ ) and the pvalue to find out whether the decoy effect itself was statistically significant for given income categories.

Table 2: Comparison of alternative shares based on the income categories

\begin{tabular}{|c|c|c|c|c|c|c|c|}
\hline Product & Income category & Choice set & $\begin{array}{c}\text { Competitor } \\
(\%)\end{array}$ & $\begin{array}{c}\text { Target } \\
(\%)\end{array}$ & $\begin{array}{c}\text { Decoy } \\
(\%)\end{array}$ & $\chi^{2}$ & p-value \\
\hline \multirow[t]{4}{*}{$\begin{array}{l}\text { Season } \\
\text { tickets }\end{array}$} & Up to $10000 \mathrm{CZK}$ & $\begin{array}{c}\text { Control } \\
\text { Experimental }\end{array}$ & $\begin{array}{l}78.38 \\
36.36\end{array}$ & $\begin{array}{l}21.62 \\
60.60\end{array}$ & $\begin{array}{c}- \\
3.04\end{array}$ & 15.56 & 0,00007 \\
\hline & $10001 \mathrm{CZK}-20000 \mathrm{CZK}$ & $\begin{array}{c}\text { Control } \\
\text { Experimental }\end{array}$ & $\begin{array}{l}62.79 \\
28.26\end{array}$ & $\begin{array}{l}37.21 \\
69.57\end{array}$ & $2 .-17$ & 10.52 & 0,0011 \\
\hline & $20001 \mathrm{CZK}-30000 \mathrm{CZK}$ & $\begin{array}{c}\text { Control } \\
\text { Experimental }\end{array}$ & $\begin{array}{l}33.33 \\
23.53 \\
\end{array}$ & $\begin{array}{l}66,67 \\
70.59 \\
\end{array}$ & $\begin{array}{c}- \\
5.88\end{array}$ & 0.74 & 0,3871 \\
\hline & Over $30000 \mathrm{CZK}$ & $\begin{array}{c}\text { Control } \\
\text { Experimental }\end{array}$ & $\begin{array}{l}52.38 \\
36.84\end{array}$ & $\begin{array}{l}47.62 \\
63.16 \\
\end{array}$ & $\begin{array}{l}- \\
0\end{array}$ & 2.24 & 0,1338 \\
\hline \multirow[t]{4}{*}{$\begin{array}{l}\text { Washing } \\
\text { machines }\end{array}$} & Up to $10000 \mathrm{CZK}$ & $\begin{array}{c}\text { Control } \\
\text { Experimental }\end{array}$ & $\begin{array}{l}56.76 \\
30.30\end{array}$ & $\begin{array}{l}43.24 \\
63.64\end{array}$ & $\begin{array}{c}- \\
6.06\end{array}$ & 5.40 & 0.0200 \\
\hline & $10001 \mathrm{CZK}-20000 \mathrm{CZK}$ & $\begin{array}{c}\text { Control } \\
\text { Experimental }\end{array}$ & \begin{tabular}{|l|}
30.23 \\
21.74 \\
\end{tabular} & $\begin{array}{l}69.77 \\
71.74 \\
\end{array}$ & $\begin{array}{c}- \\
6.52 \\
\end{array}$ & 0.55 & 0.4580 \\
\hline & $20001 \mathrm{CZK}-30000 \mathrm{CZK}$ & $\begin{array}{c}\text { Control } \\
\text { Experimental }\end{array}$ & $\begin{array}{l}44.44 \\
14.71 \\
\end{array}$ & $\begin{array}{l}55.56 \\
79.41 \\
\end{array}$ & $\begin{array}{c}- \\
5.88 \\
\end{array}$ & 8.74 & 0.0031 \\
\hline & Over $30000 \mathrm{CZK}$ & $\begin{array}{c}\text { Control } \\
\text { Experimental }\end{array}$ & $\begin{array}{l}57.14 \\
21.05 \\
\end{array}$ & $\begin{array}{l}42.86 \\
63.16 \\
\end{array}$ & $\begin{array}{c}- \\
15.79\end{array}$ & 8.89 & 0.0028 \\
\hline
\end{tabular}

Source: own data

It can be noted from the table above and from the following figures that introducing the decoy into the choice set indeed led to a decrease of competitor's share and an increase of the popularity of the target alternative in every examined income category. It can be also observed that whenever the decoy was present in the choice set the majority of subjects (over $60 \%$ ) chose the target indeed. However, overall the decoy effect was not confirmed to be statistically significant for every income category and the results are discussed in detail in the following sections.

Looking specifically at the gym season-tickets, it can be observed that the increase in the target's share differed between the income categories. The largest increase can be noted for the group with the lower income as the popularity of the target grew from $21.62 \%$ to $60.60 \%$ among subjects with income up to $10000 \mathrm{CZK}$ and the decoy effect was statistically confirmed $\left(\chi^{2}=15.56 ; p<0.05\right)$. Also the category with income between 10001 and 20000 CZK exhibited quite high shift by $32.35 \%$ with a statistically significant decoy effect $\left(\chi^{2}=\right.$ $10.52 ; \mathrm{p}<0.05)$. The highest share of the target $(70.57 \%)$ is reported for the income category 
$20001-30000 \mathrm{CZK}$, however, the shift between the popularity was only by $3.92 \%$ and this age group was prone to choose the target even when the decoy was not included in the choice set. This age group exhibited no statistically significant decoy effect $\left(\chi^{2}=0.74 ; p>0.05\right)$. Similarly, no statistically significant decoy effect was found for the income group with the income higher than $30000 \mathrm{CZK}\left(\chi^{2}=2.24 ; \mathrm{p}>0.05\right)$. If we consider gym season-ticket with a sauna entry to be a more luxurious product then we might assume higher income categories were willing and able to purchase it even without the decoy alternative in the set while lower income categories were nudged to choose it by the decoy's presence.

When it comes to the next product, washing machines, all income categories displayed a statistically significant decoy effect except for the income category $10001-20000 \mathrm{CZK}$ $\left(\chi^{2}=0.55 ; p>0.05\right)$ as for this category the raise in the target alternative upon introducing the decoy was only by $1.97 \%$ and majority of this group preferred the target over the competitor no matter if the decoy was included in the choice set or not. Also the subjects from the income category $20001-30000 \mathrm{CZK}$ preferred the target over competitor when the decoy was both absent and present, however in this case the raise in the target $(23.85 \%)$ and the decline in the competitor $(-23.85 \%)$ preference were significant and the decoy effect was confirmed to be statistically significant $\left(\chi^{2}=8.75 ; \mathrm{p}<0.05\right)$. The category with the lowest $\left(\chi^{2}=5.40 ; \mathrm{p}<\right.$ $0.05)$ and the highest income $\left(\chi^{2}=8.89 ; \mathrm{p}<0.05\right)$ also exhibited a positive decoy effect.

Given the results of the analysis, it needs to be concluded the decoy effect was not confirmed to be statistically significant for all income categories and therefore, we reject the previously set hypothesis $\mathrm{H} 1$ and accept alternative $\mathrm{H} 1$ ': The decoy effect cannot be observed between all consumers, no matter of the income category. There were some income categories that did not exhibit the decoy effect, although they differed between the two product categories.

Next, we focused on the comparison of the target shares with and without the decoy included and the possible differences between the income categories. The Fig. 1 shows the results in percentages for the first product, the season tickets. Although not all income categories exhibited the statistically significant effect all were included in the next analysis since the preference of the target rose for all of the categories. A Chi-squared test of independence $(\alpha=$ 0.05 ; $\mathrm{df}=3$; crit. value $=7.81$ ) was conducted to find out whether there is a relationship between the target preference with and without the decoy and their income category. In this case, according to the result $\left(\chi^{2}=5.63 ; \mathrm{p}=0.1309 ; \mathrm{p}>0.05\right)$ the null hypothesis of independence cannot be rejected and it is concluded that the choices of the target alternative were independent on the income category. 
Figure 1: Share of target alternative in season tickets choice sets (in \%)

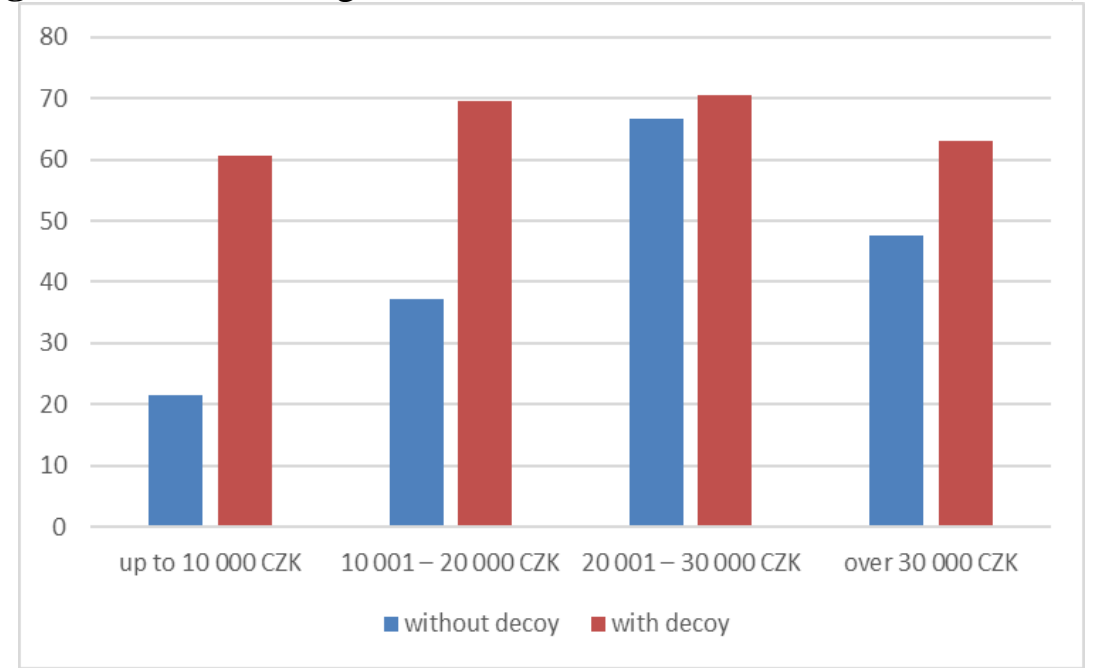

Source: own data

The same analysis was done in the case of the washing machines (see Fig. 2), once again testing the independence between the target preference with and without the decoy and their income category using a Chi-squared test $(\alpha=0.05$; $\mathrm{df}=3$; crit. value $=7.81)$. Also in this case, the null hypothesis of independence cannot be rejected $\left(\chi^{2}=1.39 ; p=0.7063 ; p>0.05\right)$ and therefore, it is concluded that the choices of the target were independent on the income category.

Figure 2: Share of target alternative in washing machines choice sets (in \%)

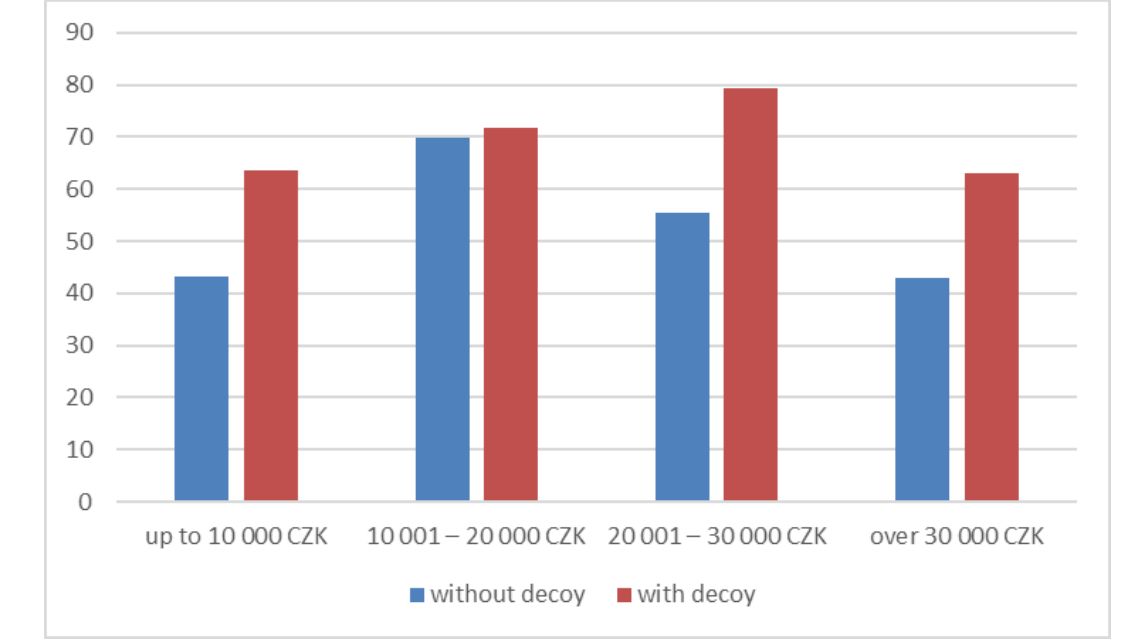

Source: own data

Based on the two conducted tests, we reject the previously set work hypothesis $\mathrm{H} 2$ and accept alternative H2': The popularity of the target alternatives is independent on the income category. Therefore, the subjects' choices of the target with and without the decoy were not related to the income.

Lastly, the strength of the decoy effect was measured in percentages as the growth of the target's popularity after introducing the decoy into the choice set. Once again, all categories were included since all displayed a raise in the target upon introducing the decoy although the raise of the target's share was not statistically significant for all of them. It is important to notice that the decoy effect affected the income categories differently in the case of each 
product. As it can be seen in the Fig. 3., the greatest decoy effect was found for the two lower income categories when it came to the season tickets (up to almost $40 \%$ for the subjects with the income up to $10000 \mathrm{CZK}$ ). The decoy effect was generally lower when the subjects made decision involving washing machines as at the maximum the decoy effect raised the popularity of the target by almost $25 \%$.

Figure 3: Growth of targets' preference (in \%)

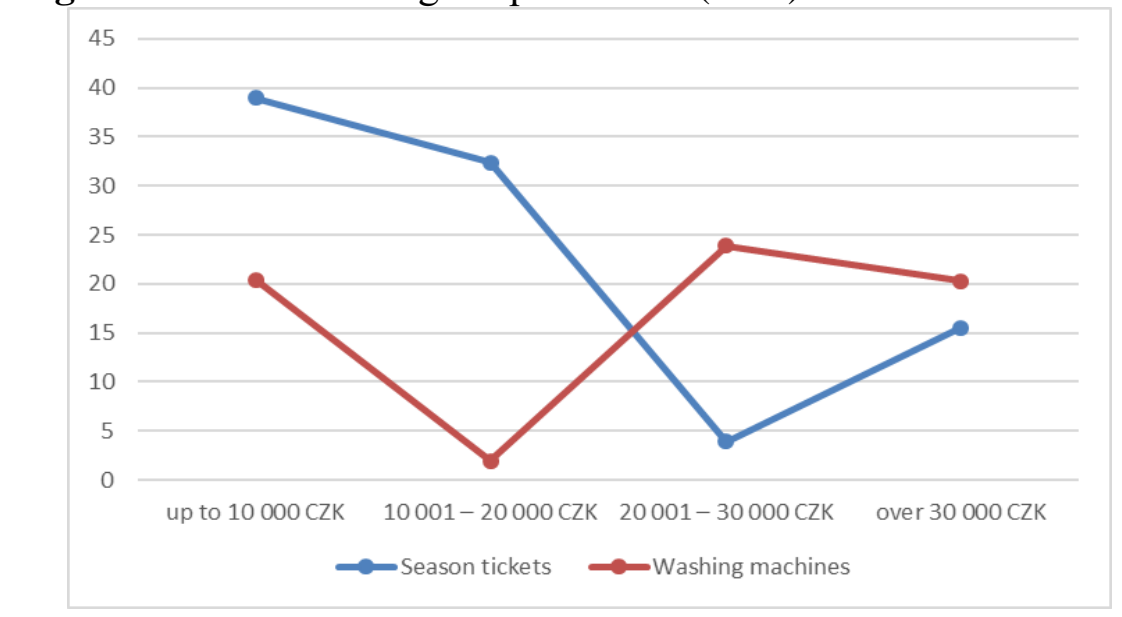

Source: own data

The strength of the decoy effect expressed as the growth of the target alternative shares for both product categories and its relationship to the income was also tested by the Chi-squared test of independence $(\alpha=0.05 ; \mathrm{df}=3$; crit. value $=7.81)$. Based on the result of the testing $\left(\chi^{2}=20.68 ; p=0.0001 ; p<0.05\right)$, there is statistically significant evidence that the growth of the target's share and the income category are not independent. Given this result, the set hypothesis $\mathrm{H} 3$ is accepted and therefore, the growth of the target share is not independent on the income category.

\subsection{Research limitations}

There are several limitations when it comes to this research. First and main one would be the sample size and its structure in which dominate the younger respondents with lower income compared to the average Czech consumer.

Another limit that could prevent generalising the practical implications is detected in the nature of the decision task which respondents were facing in the presented online surveys and the product categories which were used in this case. The decisions they made were only hypothetical and respondents had no possibility to not make a choice (as the option to choose ,no product' was not available to them) nor did their decision had any true economic consequences (paying for their product and receiving it). These factors certainly do not reflect the marketing reality but according to the previous studies by Dhar and Simonson (2003) and Lichters et al. (2015) the availability of no-option actually strengthens the decoy effect. Similarly, Lichters et al. (2015, pp.) and Huber et al. (2014, pp. 522) expect the effect to be pronounced in binding choices even more than in the hypothetical, explained by: „...greater motivation will lead a decision maker to examine all the alternatives and be more likely to determine the dominance relationship, thus amplifying the attraction effect." Although the results of these studies suggest even stronger decoy effect under such conditions, this research did not involve these realistic factors to support such claims. 


\section{Conclusion}

This paper explores the impact of income on the decoy effect, a phenomenon widely discussed in the literature of decision making, behavioural economics, psychology and marketing.

Given the data collected in an online experiment, the decoy effect was not confirmed to be statistically significant for all income categories. However, the popularity of the dominating target alternative rose upon the introduction of the decoy in all cases, even if the raise was uneven among the income categories and statistically insignificant in some cases.

Moreover, the income categories which did not display the decoy effect differed for each examined product. In decision making involving washing machines, the effect was not statistically significant for participants with income between 10001 and $20000 \mathrm{CZK}$. In case of gym season tickets, the subjects with the highest income categories failed to exhibit the effect since these groups were prone to prefer the target alternative (which was a more expensive type of gym season ticket with sauna included) even when the decoy was not in the choice set. As the results are stemming from only two examined product categories, this leaves space for a more extensive research that would be focusing on more product categories to find out more about the product differences of the decoy effect between the income categories.

Using statistical testing, it was also not proved for neither of the products that there would be a relationship between the popularity of the target alternative and the income. However, looking at the growth of the target's popularity as the strength of the decoy effect it was confirmed that is not independent on the income and the differences in the strength of the decoy effect were statistically significant.

The obtained results for the examined product categories do not diminish the practical relevance or marketing implications of the decoy effect as there was no income category that would in majority prefer the competitor over the target even with the decoy present. On the contrary, it still places the decoy as a useful tool to boost the sales or popularity of the preferred target product specifically among those demographic groups or segments for which such an alternative is not popular yet.

\section{Acknowledgement}

This work was supported by the Student Grant Foundation of the Silesian University in Opava, Grant No. SGF/6/2020, which was realized within the EU OPSRE project entitled "Improving the quality of the internal grant scheme of the Silesian University in Opava", reg. number: CZ.02.2.69/0.0/0.0/19_073/0016951.

\section{References}

[1] AJZEN, I. and M. FISHBEIN, 2005. The influence of attitudes on behavior. In: ALBARRACIN, D. B., B. JOHNSON and M. ZANNA, eds. The handbook of attitudes. Mahwah, NJ: Erlbaum, pp. 173-221. ISBN 978-0-8058-4492-4.

[2] ARIELY, D. and T. S. WALLSTEN, 1995. Seeking Subjective Dominance in Multidimensional Space: An Explanation of the Asymmetric Dominance Effect. Organizational Behavior and Human Decision Processes. 63(3), 223-232. ISSN 07495978. 
[3] BARTOLI, A. and K. VARINI, 2011. Market Segmentation: Does It Work? [online]. Conference paper: 29th EuroCHRIE Conference, Dubrovnik [cit. 3rd August 2012]. Accessible

from: https://www.researchgate.net/publication/266858293_Market_Segmentation_Does_it_w ork

[4] BATESON, M., S. D. HEALY and T. A. HURLY, 2003. Context-dependent foraging decisions in rufous hummingbirds. Proceedings of the Royal Society B: Biological Sciences. 270(1521), 1271-1276. ISSN 1471-2954.

[5] CHOPLIN, J. M. and J. E. HUMMEL, 2005. Comparison-induced decoy effects. Memory \& Cognition, 33(2), 332-43. ISSN 0090-502X.

[6] CHUANG, S. CH. and R. YEN, 2007. The impact of a product's country-of-origin on compromise and attraction effects. Marketing Letters, 18(4), 279-291. ISSN 0923-0645.

[7] CRAIK, F. I. M. and T. A. SALTHOUSE, 2008. The handbook of aging and cognition. New York: Psychology Press, pp. 672. ISBN 978-0-8058-5990-4.

[8] CZECH STATISTICAL OFFICE, 2020. Average wages - 2nd quarter of 2020 [online]. [cit. 30th September 2020]. Accessible from: https://www.czso.cz/csu/czso/ari/averagewages-2-quarter-of-2020

[9] DHAR, R. and I. SIMONSON, 2003. The Effect of Forced Choice on Choice. Journal of Marketing Research, 40(2), 146-160. ISSN 1547-7193.

[10] ĎURINÍK, M., 2013. Influencing a Warranty Choice with the Introduction of an Inferior Alternative into the Choice Set. In: Sborník príspěvki̊ VI. Mezinárodní vědecké konference doktorandi̊ a mladých vědeckých pracovniků. Karviná: SU - OPF, pp. 249257. ISBN 978-80-7248-901-5.

[11] FREDERICK, S., L. LEE and E. BASKIN, 2014. The Limits of Attraction. Journal of Marketing Research, 51(4), 487-507. ISSN 1547-7193.

[12] HA, Y. - W., S. PARK and H. K. AHN, 2009. The influence of categorical attributes on choice context effects. Journal of Consumer Research, 36(3), 463-477. ISSN 1537-5277.

[13] HEATH, T. B. and S. CHATTERJEE, 1995. Asymmetric Decoy Effects on LowerQuality versus Higher-Quality Brands: Meta-analytic and Experimental Evidence. Journal of Consumer Research, 22(3), 268-284. ISSN 1537-5277.

[14] HUBER, J., J. W. PAYNE and C. PUTO, 1982. Adding Asymmetrically Dominated Alternatives: Violations of Regularity and the Similarity Hypothesis. Journal of Consumer Research, 9(1), 90-98. ISSN 1537-5277.

[15] HUBER, J., J. W. PAYNE, and C. P. PUTO, 2014. Let's be honest about the attraction effect. Journal of Marketing Research, 51(4), 520-525. ISSN 1547-7193.

[16] KAPTEIN, M. C., R. V. EMDEN and D. IANNUZZI, 2016. Tracking the decoy: maximizing the decoy effect through sequential experimentation. Palgrave Communications, 2, 1-9. ISSN 2055-1045.

[17] KIM, S. and L. HASHER, 2005. The attraction effect in decision making: Superior performance by older adults. The Quarterly Journal of Experimental Psychology Section $A$, 58(1), 120-133. ISSN 1747-0226.

[18] KUBALOVÁ, R., 2020. Impact of Demographic Factors Gender and Age on the Decoy Effect. Journal of Economics and Social Research, 21(1), 25-33. ISSN 1335-7069. 
[19] LEVAV, J., R. KIVETZ and C. CHO, 2010. Motivational Compatibility and Choice Conflict. Journal of Consumer Research, 37(3), 429-442. ISSN 1537-5277.

[20] LICHTERS, M., P. BENGART, M. SARSTEDT and B. VOGT, 2015. What really matters in attraction effect research: when choices have economic consequences. Marketing Letters, 28(1), 127-138. ISSN 0923-0645.

[21] LIN, CH. H., Y. CH. SUN, S. CH. CHUANG and H. J. SU, 2008. Time Pressure and the Compromise and Attraction Effects in Choice. In LEE, A., SOMAN, D (eds). Advances in Consumer Research Volume 35. Duluth, USA: Association for Consumer Research, pp. 348-352.

[22] MAO, W. and H. OPPEWAL, 2012. The attraction effect is more pronounced for consumers who rely on intuitive reasoning. Marketing Letters, 23(1), 339-351. ISSN 0923-0645.

[23] MILBERG, S. J., M. SILVA, P. CELEDON and F. SINN, 2014. Synthesis of attraction effect research: Practical market implications? European Journal of Marketing, 48(7/8), 1413-1430. ISSN 0309-0566.

[24] PARRISH, A. E., T. H. EVANS and M. J. BERAN, 2015. Rhesus macaques (Macaca mulatta) exhibit the decoy effect in a perceptual discrimination task. Attention, Perception, \& Psychophysics, 77, 1715-1725. ISSN 1943-3921.

[25] PETTIBONE, J. C. and D. H. WEDELL, 2007. Testing alternative explanations of phantom decoy effects. Journal of Behavioral Decision Making, 20(3), 323-341. ISSN 1099-0771.

[26] ROGERS, E. S., E. A. VARGAS and E. VOIGT, 2020. Exploring the decoy effect to guide tobacco treatment choice: a randomized experiment. BMC Research Notes, 13(3), 1-5. ISSN 1756-0500.

[27] STATISTA.COM, 2020. Distribution of Facebook users worldwide as of July 2020, by age and gender [online]. [cit. 30th September 2020]. Accessible from: https://www.statista.com/statistics/376128/facebook-global-user-age-distribution/

[28] TENTORI, K., D. OSHERON, L. HASHER and C. MAY, 2001. Wisdom and aging: Irrational preferences in college students but not older adults. Cognition, 81, B87-B96. ISSN 0010-0277.

[29] WU, CH. and K. COSGUNER, 2020. Profiting from the Decoy Effect: A Case Study of an Online Diamond Retailer. Marketing Science, forthcoming. ISSN 1526-548X.

[30] WU, S. and R. YU, 2018. Fatigue biases the decoy effect in males but not females. International Journal of Psychology, 54(5), 604-6011. ISSN 1464-066X.

[31] YANG, S. S. and M. LYNN, 2014. More Evidence Challenging the Robustness and Usefulness of the Attraction Effect. Journal of Marketing Research, 51(4), 508-513. ISSN 1547-7193.

[32] ZHEN, S. and R. YU, 2016. The development of the asymmetrically dominated decoy effect in young children. Scientific Reports, 6, Article 22678. ISSN 2045-2322. 